\title{
Influence of Egg Pre-Storage Heating Period and Storage Length on the Digestive Tract of Newly-Hatched Broiler Chicks
}

\begin{tabular}{|c|c|}
\hline \multicolumn{2}{|c|}{ Author(s) } \\
\hline & $\begin{array}{l}\text { Iva } \mathrm{FHA}^{1} \\
\text { ria } \mathrm{DE}^{1^{*}} \\
\text { orres KAA }{ }^{2} \\
\text { aria Filho } \mathrm{DE}^{3} \\
\text { oelho } \mathrm{AAD}^{4} \\
\text { avino } \mathrm{VJM}^{4}\end{array}$ \\
\hline 1 & $\begin{array}{l}\text { Departamento de Zootecnia, Faculdade de } \\
\text { Zootecnia e Engenharia de Alimentos - } \\
\text { Universidade de São Paulo. Pirassununga, } \\
\text { SP. }\end{array}$ \\
\hline 2 & $\begin{array}{l}\text { Departamento de Morfologia e Fisiologia } \\
\text { Animal, Faculdade de Ciências Agrárias e } \\
\text { Veterinárias - Universidade Estadual } \\
\text { Paulista. Jaboticabal, SP. }\end{array}$ \\
\hline 3 & $\begin{array}{l}\text { Departamento de Zootecnia, Núcleo de } \\
\text { Ciências Agrárias - Universidade Federal de } \\
\text { Minas Gerais. }\end{array}$ \\
\hline 4 & $\begin{array}{l}\text { Departamento de Genética - Escola Supe- } \\
\text { rior de Agricultura Luiz de Queiroz - } \\
\text { Universidade de Sao Paulo. Piracicaba, SP. }\end{array}$ \\
\hline
\end{tabular}

Mail Address

E-mail: defaria@usp.br

Keywords

Broilers, embryo development, incubation, intestinal mucosa, morphometrics.

\section{ABSTRACT}

An experiment was carried out to evaluate the effect of different heating times of settable eggs of Cobb $500^{\circledR}$ broiler breeders before submitting them to different storage periods on body weight, digestive tract organ weights, and intestinal mucosa morphology of newly-hatched chicks. Settable eggs were distributed in a completely randomized experimental design with a $3 \times 3$ factorial arrangement: pre-storage heating periods $\left(0,6,12\right.$ hours at $\left.36.92^{\circ} \mathrm{C}\right)$ and storage periods $(4,9,14$ days at $\left.12.06^{\circ} \mathrm{C}\right)$. Body weight and relative weights of the yolk sac, heart, liver, proventriculus+gizzard, and intestinal segments were measured in chicks hatching at 480 and 498 hours of incubation. Villi height, width and perimeter, and crypt depth (im) were measured in duodenal histological sections. It was concluded that pre-storage heating for six hours of eggs stored for four or nine days increases small intestine weight of newly-hatched chicks, but does not influence the morphology of the duodenal mucosa. Pre-storage heating for 12 hours negatively influences body weight and duodenal mucosa development, and therefore this practice is not recommended. Storage length does not have consistent effect on body weight and development of the gastrointestinal tract.

\section{INTRODUCTION}

Some factors that precede incubation, such as egg quality and management, may affect embryo development. Long storage of settable eggs reduces embryo metabolic rate (oxygen consumption) and changes the circulatory system function of developing embryos during incubation (Haque et al., 1996). These direct effects of long egg storage on the embryo may explain poor incubation results (Fasenko et al., 2001; Silva et al., 2008) and may be related to lower day-old chick quality (Tona et al., 2003).

Tona et al. (2003) observed that storing eggs at $15 \pm 1^{\circ} \mathrm{C}$ for 18 days, as compared to three days, negatively affects day-old chick quality - as defined by physical characteristics, such as activity, feathering, eyes, aspect of navel area, conformation of legs, and yolk sac absorption and relative growth during the first week of life. The authors found that the effect on growth is not directly related to newly-hatched chick quality, and suggested that other factors influencing relative growth during the first week of age are affected by long egg storage (Tona et al., 2003).

The variation of the physiological capacity of the gastrointestinal tract may be one of the limitations of the progressive increase of post-hatching growth rate (Denbow, 2000). Before and immediately after hatching, several morphological and functional characteristics of the digestive tract are developed, allowing the utilization of the first feed ingested by the 
chicks. The most frequently studied characteristics are organ size, small intestine villi height, enterocyte microvilli formation, beginning of mucin production, increase in small intestine crypt number and depth, and beginning of enzymatic digestion and absorption (Uni et al., 2003 a,b; Maiorka et al., 2003; Uni et al., 1999).

The morphology of the intestinal mucosa of newlyhatched chicks is well characterized. Crypts contain pluripotential cells (source of enterocytes and mucinproducing goblet cells), are shallow, and do not present complete invagination along the intestine. At hatching, villi and crypt cells of the duodenum, jejunum, and ileum are highly proliferative, making these structures rapidly increase in height and depth (Geyra et al., 2001).

After hatching, the development of the gastrointestinal tract depends on the availability of sufficient nutrients, and many studies were carried out on the effect of post-hatch water and feed fasting times on gastrointestinal tract development (Maiorka et al., 2003; Bigot et al., 2003; Corless \& Sell, 1999). However, we did not find in literature studies on the effects of pre-incubation factors, such as pre-storage heating and egg storage length on the gastrointestinal characteristics of chicks.

Pre-storage heating allows the embryo to achieve complete hypoblast formation - embryo development stage more resistant to storage conditions at temperatures below physiological zero (Fasenko, 2001). The results of the study of Silva et al. (2008) indicate that heating eggs for six hours before four and nine days of storage increases hatchability and decreases incubation length as compared with nonheated eggs or eggs heated for 12 hours. This suggests pre-storage heating may cause changes in embryo development, which could influence gastrointestinal tract maturity in the newly-hatched chick.

This study aimed at evaluating the effect of different times of heating before different periods of storage of broiler breeder settable eggs on body weight, digestive tract organ weights, and intestinal mucosa morphology of the newly-hatched chicks.

\section{MATERIAL AND METHODS}

A total number of 1,980 settable eggs produced by a 44-week-old Cobb $500^{\circledR}$ breeder flock was collected in a commercial farm located in the region of São Carlos, SP, Brazil, and transported to the experimental hatchery. Eggs were distributed in a completely randomized experimental design in a $3 \times 3$ factorial arrangement, with three pre-storage heating periods $\left(0,6\right.$, and 12 hours at $\left.36.92^{\circ} \mathrm{C}\right)$ and three storage periods $\left(4,9\right.$ and 14 days at $\left.12.06^{\circ} \mathrm{C}\right)$, summing up nine treatments with 22 replicates of 10 eggs each. Eggs were directly collected from the nest during the second daily collection in order to ensure lay time uniformity. In order to incubate all eggs at the same time, eggs were collected in three five-day intervals, representing the three storage periods $(4,9$ and 14 days). Therefore, the first collection corresponded to eggs stored for 14 days; the second to eggs stored for nine days; and the third to eggs stored for four days. Immediately after collection, eggs were disinfected by simple fumigation with $7.7 \mathrm{~g}$ paraformaldehyde $/ \mathrm{m}^{3}$ for 15 minutes, and transported to the experimental hatchery (Poultry Sector, University of São Paulo, Piracicaba, SP), where they were submitted to simple fumigation with $20 \mathrm{~mL}$ liquid formaldehyde for 20 minutes, identified, weighed in pools of ten eggs, and randomly distributed into the treatments.

Pre-storage heating for six and 12 hours (depending on treatment) was carried out in an Avimatic ${ }^{\circledR}$ incubator with 14,400-egg capacity at an average temperature of $36.92^{\circ} \mathrm{C}$ and relative air humidity of $61.33 \%$. After heating, eggs were kept at room temperature for one hour. Eggs were then stored in a chamber at $12.06^{\circ} \mathrm{C}$ and $76.5 \%$ relative air humidity for the periods corresponding to the treatments. After storage, eggs were maintained at $21.33^{\circ} \mathrm{C}$ and $75.6 \%$ air relative humidity for five hours before incubation as pre-incubation adaptation period. Eggs were incubated in an Avimatic ${ }^{\circledR}$ incubator for 442 hours (18 days and 10 hours) at $37.61^{\circ} \mathrm{C}$ average temperature and $55.9 \%$ relative air humidity. Eggs were turn hourly. Eggs were fumigated with paraformaldehyde $(15 \mathrm{~g}$ for 15 minutes) at 12 hours, and seven and 14 days of incubation. At 442 hours of incubation, eggs were transferred to an Avimatic ${ }^{\circledR}$ hatcher at $36.37^{\circ} \mathrm{C}$ average temperature and $60.7 \%$ average air relative humidity. Hatched chicks were removed from the hatcher at 480 hours of incubation ( $1^{\text {st }}$ removal) and at 498 hours ( $2^{\text {nd }}$ removal).

Four chicks per treatment were chosen at random, weighed $(g \pm 0.01)$, and sacrificed by neck dislocation. Yolk sac, heart, liver, proventriculus+gizzard, and intestines were dissected. Intestinal segments were separated: duodenum, from the end of the duodenal loop the Meckel's diverticulum; ileum, from Meckel's diverticulum to the base of the ceca; and ceca+rectum (from the base of the ceca to the junction of the rectum with the cloaca. All organs were weighed $(g \pm 0.01)$, and weight was expressed as a percentage of body weight. 
Three-cm long duodenum sections were collected for morphometric evaluation of the villi. Samples were fixed in Bouin's solution (70\% picric acid saturated solution, $25 \%$ formaldehyde, and $5 \%$ acetic acid) for 24 hours, and then routinely processed for light microscopy. Tissues were dehydrated in graded ethanol series $(70,80,90$, and 100\%), cleared in xylol, and embedded in paraffin. Six- $\mu m$ thick tissue sections were stained with hematoxylin and eosin. Section images at 25-x magnification were obtained in a Zeiss Axioplan $2^{\circledR}$ microscope coupled with a Zeiss MC80 DX ${ }^{\circledR}$ camera, and were analyzed by Axiovision ${ }^{\circledR}$ software. Villi height, width, and perimeter, and crypt depth were measured in the images. Results were expressed in im.

Data were verified as to the presence of outliers, variance homogeneity, and error normality. After these assumptions of the model were verified, data were submitted to analysis of variance using the General Linear Model procedure of SAS ${ }^{\circledR}$ version 8 (1999). When significantly different, means were compared by the test of Tukey at $5 \%$ probability.

\section{RESULTS}

Body weight and yolk sac, heart, proventriculus +gizzard, jejunum, ileum, ceca+rectum relative weights of day-old chicks are shown in Tables 1, 2, and 3. In chicks hatched at 480 hours of incubation, there was no effect of the interaction between heating times and storage periods, nor main effect of storage period on the analyzed parameters. Pre-storage heating for six and 12 hours increased liver and duodenum relative weights $(p<0.05)$, and tended to increase jejunum relative weight $(p=0.05)$ (Table 1$)$. In chicks hatched at 498 hours of incubation, there was no effect of the interaction between factors on body weight and organ relative weight, except for small intestine sections (Table 2). Heating for 12 hours resulted in lower chick body weight as compared to heating for zero or six hours. Storage for nine days increased liver relative weight as compared with storage for four days.

Duodenum, jejunum, and ileum relative weights of chicks hatched at 498 hours of incubation were

\begin{tabular}{|c|c|c|c|c|c|c|c|c|c|}
\hline \multirow[t]{2}{*}{ Factor } & \multirow{2}{*}{$\begin{array}{l}\text { Chick average } \\
\text { weight }(\mathrm{g})\end{array}$} & \multicolumn{7}{|c|}{ Relative organ weight (\%) } & \multirow[b]{2}{*}{$\begin{array}{l}\text { Ceca+ } \\
\text { rectum }\end{array}$} \\
\hline & & Heart & Yolk sac & Liver & $\begin{array}{c}\text { Proventriculus+ } \\
\text { gizzard }\end{array}$ & Duodenum & Jejunum & Ileum & \\
\hline \multicolumn{10}{|c|}{ Hours of heating $(\mathrm{H})$} \\
\hline 0 & 47.63 & 0.61 & 14.65 & $2.25 \mathrm{~B}$ & 5.76 & $0.72 B$ & 1.23 & 0.20 & 1.01 \\
\hline 6 & 48.36 & 0.67 & 13.90 & $2.48 \mathrm{AB}$ & 6.30 & $1.05 \mathrm{~A}$ & 1.46 & 0.24 & 0.99 \\
\hline 12 & 47.86 & 0.73 & 13.25 & $2.63 \mathrm{~A}$ & 5.75 & $1.08 \mathrm{~A}$ & 1.54 & 0.24 & 1.26 \\
\hline \multicolumn{10}{|c|}{ Days of storage (S) } \\
\hline 4 & 48.62 & 0.70 & 12.73 & 2.43 & 6.01 & 0.89 & 1.31 & 0.24 & 1.05 \\
\hline 9 & 47.48 & 0.64 & 14.38 & 2.41 & 6.16 & 0.93 & 1.47 & 0.22 & 1.17 \\
\hline 14 & 47.75 & 0.67 & 14.69 & 2.53 & 5.64 & 1.04 & 1.45 & 0.23 & 1.04 \\
\hline \multicolumn{10}{|c|}{ Probability } \\
\hline $\mathrm{H}$ & 0.56 & 0.11 & 0.46 & 0.04 & 0.15 & 0.02 & 0.05 & 0.38 & 0.18 \\
\hline S & 0.22 & 0.49 & 0.19 & 0.70 & 0.24 & 0.49 & 0.38 & 0.84 & 0.67 \\
\hline $\mathrm{H} \times \mathrm{S}$ & 0.65 & 0.21 & 0.34 & 0.22 & 0.32 & 0.88 & 0.43 & 0.98 & 0.83 \\
\hline C.V. (\%) & 8.20 & 18.84 & 19.59 & 14.45 & 12.76 & 32.91 & 21.34 & 30.70 & 35.08 \\
\hline
\end{tabular}

Means followed by the same letters in the same column and factor are not different by the test of Tukey (p>0.05).

\begin{tabular}{|c|c|c|c|c|c|c|c|c|c|}
\hline \multirow[t]{2}{*}{ Factor } & \multirow{2}{*}{$\begin{array}{c}\text { Chick average } \\
\text { weight }(g)\end{array}$} & \multicolumn{7}{|c|}{ Relative organ weight (\%) } & \multirow[b]{2}{*}{$\begin{array}{c}\text { Ceca+ } \\
\text { rectum }\end{array}$} \\
\hline & & Heart & Yolk sac & Liver & $\begin{array}{c}\text { Proventriculus+ } \\
\text { gizzard }\end{array}$ & Duodenum ${ }^{1}$ & Jejunum ${ }^{1}$ & Ileum $^{1}$ & \\
\hline \multicolumn{10}{|c|}{ Hours of heating $(\mathrm{H})$} \\
\hline 0 & $48.36 \mathrm{~A}$ & 0.74 & 13.97 & 2.50 & 6.26 & 1.05 & 1.57 & 0.26 & 1.30 \\
\hline 6 & $47.95 \mathrm{~A}$ & 0.76 & 11.83 & 2.70 & 6.58 & 1.19 & 1.91 & 0.29 & 1.31 \\
\hline 12 & $45.84 \mathrm{~B}$ & 0.75 & 13.64 & 2.64 & 6.48 & 1.12 & 1.61 & 0.25 & 1.28 \\
\hline \multicolumn{10}{|c|}{ Days of storage (S) } \\
\hline 4 & 46.89 & 0.71 & 13.47 & $2.45 B$ & 6.49 & 1.07 & 1.75 & 0.28 & 1.37 \\
\hline 9 & 47.58 & 0.77 & 12.59 & $2.76 \mathrm{~A}$ & 6.38 & 1.12 & 1.68 & 0.28 & 1.33 \\
\hline 14 & 47.68 & 0.78 & 13.38 & $2.63 \mathrm{AB}$ & 6.45 & 1.18 & 1.67 & 0.25 & 1.19 \\
\hline \multicolumn{10}{|c|}{ Probability } \\
\hline $\mathrm{H}$ & 0.01 & 0.93 & 0.06 & 0.14 & 0.67 & 0.14 & 0.01 & 0.15 & 0.99 \\
\hline S & 0.62 & 0.38 & 0.58 & 0.02 & 0.95 & 0.36 & 0.76 & 0.51 & 0.57 \\
\hline $\mathrm{H} \times \mathrm{S}$ & 0.48 & 0.23 & 0.06 & 0.09 & 0.31 & 0.01 & $<0.01$ & 0.01 & 0.07 \\
\hline C.V. (\%) & 6.73 & 16.98 & 17.34 & 9.38 & 13.20 & 15.47 & 16.71 & 21.79 & 34.03 \\
\hline
\end{tabular}

Means followed by the same letters in the same column and factor are not different by the test of Tukey (p>0.05). 1 - The interaction between factors for these parameters is detailed in Table 3. 
influenced by the interaction between the factors. Chicks hatched from eggs stored for four days presented higher duodenum, jejunum, and ileum relative weights when eggs were heated for six hours as compared to zero or 12 hours. Jejunum presented the highest relative weight when eggs were stored for nine days and heated for six hours as compared to 12 hours of heating, whereas duodenum and ileum relative weights were not different (Table 3 ).

\begin{tabular}{|c|c|c|c|}
\hline \multirow{3}{*}{$\begin{array}{l}\text { Hours of } \\
\text { heating }\end{array}$} & \multirow{2}{*}{\multicolumn{3}{|c|}{ Days of storage }} \\
\hline & & & \\
\hline & \multicolumn{3}{|c|}{ Duodenum } \\
\hline 0 & $0.85 \mathrm{Bb}$ & $1.09 \mathrm{Aab}$ & $1.20 \mathrm{Aa}$ \\
\hline 6 & $1.31 \mathrm{Aa}$ & $1.22 \mathrm{Aab}$ & $1.05 \mathrm{Ab}$ \\
\hline 12 & $1.05 \mathrm{Ba}$ & $1.03 \mathrm{Aa}$ & $1.27 \mathrm{Aa}$ \\
\hline \multicolumn{4}{|c|}{ Jejunum } \\
\hline 0 & $1.43 \mathrm{Ba}$ & $1.56 \mathrm{ABa}$ & $1.72 \mathrm{Aa}$ \\
\hline 6 & $2.29 \mathrm{Aa}$ & $1.94 \mathrm{Aa}$ & $1.48 \mathrm{Ab}$ \\
\hline 12 & $1.51 \mathrm{Ba}$ & $1.52 \mathrm{Ba}$ & $1.80 \mathrm{Aa}$ \\
\hline \multicolumn{4}{|c|}{ Ileum } \\
\hline 0 & $0.22 \mathrm{Ba}$ & $0.29 \mathrm{Aa}$ & $0.27 \mathrm{Aa}$ \\
\hline 6 & $0.37 \mathrm{Aa}$ & $0.29 \mathrm{Ab}$ & $0.22 \mathrm{Ab}$ \\
\hline 12 & $0.23 \mathrm{Ba}$ & $0.25 \mathrm{Aa}$ & $0.26 \mathrm{Aa}$ \\
\hline
\end{tabular}

Means followed by the same letters - capital letters in the same column, and small letters in the same row - are not different by the test of Tukey $(p>0.05)$.

When eggs were not heated, duodenum relative weight increased with storage length, while jejunum and ileum relative weights were not influenced by storage. However, when eggs were heated for six hours, the duodenum, jejunum, and ileum had lower relative weight in chicks derived from eggs stored for 14 days as compared to those stored for four days. When eggs were heated for 12 hours, days of storage did not affect the relative weights of the intestinal segments. The highest duodenum, jejunum, and ileum relative weights were obtained when egg were heated for six hours and stored for four days (Table 3 ).

Morphometric characteristics of the villi of newlyhatched chicks are presented in Tables 4, 5, and 6. In chicks hatched at 480 hours of incubation, there was no effect of the interaction between factors, or of the main effect pre-storage heating time. However, storage for more than four days caused higher villi height and perimeter (Table 4).

In chicks hatched at 498 hours of incubation, the effect of the interaction of factors was significant only for crypt depth. The main effect of storage was not significant for villi height, width, or perimeter. When eggs were heated for 12 hours, chick villi height and perimeter were lower as compared to those heated for zero or six hours (Table 5).

\begin{tabular}{|c|c|c|c|c|}
\hline \multirow[t]{2}{*}{ Factor } & \multicolumn{3}{|c|}{ Villi characteristics $(\mu \mathrm{m})$} & \multirow{2}{*}{$\begin{array}{c}\text { Crypt depth } \\
(\mu \mathrm{m})\end{array}$} \\
\hline & Height & Width & Perimeter & \\
\hline \multicolumn{5}{|c|}{ Hours of heating $(\mathrm{H})$} \\
\hline 0 & 381.1 & 61.23 & 813.98 & 30.54 \\
\hline 6 & 427.41 & 67.32 & 913.46 & 31.70 \\
\hline 12 & 420.37 & 67.59 & 892.41 & 30.25 \\
\hline \multicolumn{5}{|c|}{ Days of storage (S) } \\
\hline 4 & $357.71 \mathrm{~B}$ & 67.06 & $773.37 \mathrm{~B}$ & 31.79 \\
\hline 9 & $449.45 \mathrm{~A}$ & 64.21 & $949.57 \mathrm{~A}$ & 30.20 \\
\hline 14 & $421.73 \mathrm{~A}$ & 64.87 & $896.9 A B$ & 30.49 \\
\hline \multicolumn{5}{|c|}{ Probability } \\
\hline $\mathrm{H}$ & 0.14 & 0.22 & 0.14 & 0.90 \\
\hline $\mathrm{S}$ & $<0.01$ & 0.76 & 0.01 & 0.88 \\
\hline $\mathrm{H} \times \mathrm{S}$ & 0.29 & 0.18 & 0.20 & 0.45 \\
\hline C.V.(\%) & 14.63 & 15.12 & 14.26 & 25.37 \\
\hline
\end{tabular}

Means followed by the same letters in the same column and factor are not different by the test of Tukey $(p>0.05)$.

\begin{tabular}{|c|c|c|c|c|}
\hline \multirow[t]{2}{*}{ Factor } & \multicolumn{3}{|c|}{ Villi characteristics $(\mu \mathrm{m})$} & \multirow{2}{*}{$\begin{array}{c}\text { Crypt depth } \\
(\mu \mathrm{m})^{1}\end{array}$} \\
\hline & Height & Width & Perimeter & \\
\hline \multicolumn{5}{|c|}{ Hours of heating $(\mathrm{H})$} \\
\hline 0 & $479.09 \mathrm{~A}$ & 71.26 & $1006.60 \mathrm{~A}$ & 39.63 \\
\hline 6 & $488.85 \mathrm{~A}$ & 75.07 & $1043.04 \mathrm{~A}$ & 38.90 \\
\hline 12 & $412.37 \mathrm{~B}$ & 68.52 & $880.08 \mathrm{~B}$ & 32.71 \\
\hline \multicolumn{5}{|c|}{ Days of storage (S) } \\
\hline 4 & 464.09 & 69.73 & 984.31 & 42.25 \\
\hline 9 & 454.26 & 74.61 & 978.79 & 32.79 \\
\hline 14 & 461.96 & 70.52 & 966.62 & 36.20 \\
\hline \multicolumn{5}{|c|}{ Probability } \\
\hline $\mathrm{H}$ & $<0.01$ & 0.17 & $<0.01$ & 0.19 \\
\hline S & 0.89 & 0.32 & 0.92 & 0.08 \\
\hline $\mathrm{H} \times \mathrm{S}$ & 0.12 & 0.31 & 0.09 & 0.03 \\
\hline C.V.(\%) & 11.35 & 11.58 & 11.33 & 26.95 \\
\hline
\end{tabular}

1 - The interaction between factors for these parameters is detailed in Table 6. Means followed by the same letters in the same column and factor are not different by the test of Tukey $(p>0.05)$.

The interaction between factors influenced crypt depth, which was lower when eggs were stored for four days and heated for 12 hours. The treatments nine and 14 days of storage were not affected by heating times. The deepest crypts were observed when eggs were heated for zero or six hours and stored for four days (Table 6).

\section{DISCUSSION}

The size of the newly-hatched chick is determined by egg size and length of the development period during incubation. In addition, the development period depends on the embryo growth rate, which decreases when settable eggs are stored for long periods 
Silva FHA, Faria DE, Torres KAA, Faria Filho DE, Coelho AAD, Savino VJM
Table 6 - Effect of the interaction between factors on duodenal villi crypt depth $(\mu \mathrm{m})$ of chicks hatched at 498 hours of incubation (2nd removal).

\begin{tabular}{cccc} 
Hours of & \multicolumn{3}{c}{ Days of storage } \\
\cline { 2 - 4 } heating & $\mathbf{4}$ & $\mathbf{9}$ & $\mathbf{1 4}$ \\
0 & $50.54 \mathrm{Aa}$ & $30.16 \mathrm{Ab}$ & $38.20 \mathrm{Ab}$ \\
6 & $49.24 \mathrm{Aa}$ & $35.88 \mathrm{Aab}$ & $31.60 \mathrm{Ab}$ \\
12 & $26.97 \mathrm{Ba}$ & $32.35 \mathrm{Aa}$ & $38.81 \mathrm{Aa}$ \\
\hline
\end{tabular}

Means followed by the same letters - capital letters in the same column, and small letters in the same row - are not different by the test of Tukey $(p>0.05)$.

(Christensen et al. 2002). Haque et al. (1996) showed that long storage changes embryo metabolic rate pattern, presenting significantly lower oxygen consumption as compared to non-stored eggs. In the present study, however, neither the interaction between heating times and storage length, or the main effect storage length significantly influenced the body weight of chicks hatched at 480 or 498 hours of incubation (Tables 1 and 2), indicating that there were differences in the development rate and organogenesis of chicks within each treatment. Chicks hatching at 480 hours of incubation derived from eggs stored for four, nine, or 14 days presented similar development rates. This can also be inferred for the chicks that hatched at 498 hours of incubation. However, at 480 hours, there was a higher percentage of hatching of chicks derived from eggs stored for four days as compared to those stored for 14 days, whereas at 498 hours, the highest hatching percentage was of chicks derived from eggs stored for 14 days (Silva et al., 2008).

Pre-storage heating for 12 hours negatively influenced the body weight of chicks hatched at 498 hours, independent of storage length (Table 2). Moreover, it was observed that heating for 12 hours increased late embryo mortality and reduced the hatchability of eggs stored for nine or 14 days (Silva et al., 2008). Conversely, Fasenko et al. (2001) found that heating for 12 hours before storage for 14 days promoted the same hatchability as storing eggs for four days with no previous heating. However, these authors suggest that pre-storage heating for six hours is the treatment required for the embryo to reach the development stage characterized by complete hypoblast formation, which confers higher resistance to storage (Fasenko et al., 2001).

In terms of digestive tract organ weights (Tables 1 and 2), the main effect of egg heating (for 12 hours) on chicks hatched at 480 hours of incubation, and of egg storage (for nine days) on chicks hatched at 498 hours resulted in higher liver relative weight $(p<0.05)$. The effect of the interaction between heating (for six
Influence of Egg Pre-Storage Heating Period and Storage Length on the Digestive Tract of Newly-Hatched Broiler Chicks hours) and storage (for four days) on chicks hatched at 498 hours resulted in the highest duodenum, jejunum, and ileum relative weights $(p<0.01)$. The variation in relative weight of digestive tract organs may indicate differences in the gastrointestinal physiological capacity of the chicks caused by the preincubation treatments. This variation is considered a limiting factor for post-hatching growth (Denbow, 2000).

According to Lilja \& Olsson (1987), the organogenesis of embryos of poultry selected for fast post-hatching growth is characterized by the preferential growth of supply organs (heart, liver, intestines) over demand organs (heart, muscles). This may indicate that the treatments that resulted in the highest liver and intestinal weights in the present experiment favored the expression of this characteristic of fast-growing birds, ensuring an early utilization of the feed supplied immediately after hatching. However, it must be noted that pre-storage heating for 12 hours had negative effects on incubation results (Silva et al., 2008). Christensen et al. (2002) observed that, among broiler strains selected for fast growth, there are differences in organ growth rate during incubation, which depend on the strain capacity to survive long storage of settable eggs. Strains that present high survival capacity are characterized by reduced growth of supply organs to favor the maintenance of demand organs (muscles), whereas the opposite is observed in low survival capacity strains.

The results of the present study showed that long storage increased duodenum villi size in chicks hatched at 480 hours of incubation (Table 4) and liver relative weight of chicks hatched at 498 hours (Table 2). We could infer that in the evaluated strain $\left(\mathrm{Cobb}_{500}{ }^{\circledR}\right)$ long storage (for 14 days) favored the development of supply organs, villi size and liver size, which is considered characteristic of strains with low capacity to survive long storage periods (Christensen et al., 2002). However, body weight and heart, yolk sac, and proventriculus+gizzard relative weights were not significantly influenced by storage for nine or 14 days. Therefore, under the conditions of the present experiment, long storage did not have a consistent effect on the development of digestive tract organs.

On the other hand, when eggs were pre-heated for six hours and stored for nine or 14 days, duodenum, jejunum, and ileum weights (Table 3 ), and duodenal mucosa crypt depth of chicks hatched at 498 hours (Table 6) decreased as compared to chicks derived from eggs stored for four days. These results, individually 
considered, indicate that pre-heating for six hours may improve the survival capacity of the evaluated strain to long egg storage.

According to Uni et al. (1999), small intestine weight increase after hatching is associated with an increase in mass (intestinal mucosa development) rather than with an increase in length, thereby ensuring larger surface area for the absorption of feed nutrients. The results of the present study showed that heating for six hours preserved villi characteristics (width, perimeter, and crypt depth) in chicks hatched at 498 hours (Tables 5 and 6 ) at any storage length.

Crypts are regions of the mucosa characterized by high mitosis rate, and contain pluripotential cells, which differentiate in enterocytes and mucin-producing goblet cells. Measuring crypt depth allows inferences on crypt proliferative potential and development stage, as during the days immediately after hatching, there is intensive cryptogenesis (increase in crypt number and depth) and the maturation of enterocytes into their functional forms (Geyra et al., 2001). In the present study, eggs heated for 12 hours before storing the eggs for four days resulted in shallower crypts (Table 6), which indicated that this treatment may reduce villi growth after hatching, influencing the chick's capacity to utilize feed nutrients, and therefore, its post-hatching growth.

Finally, the results of this study showed that prestorage heating times and storage length before incubation did not affect yolk sac weight of newlyhatched chicks. Therefore, the nutritional reserve available in the yolk sac was preserved until hatching, despite the changes in embryo development rate and incubation length of embryos submitted to heating and storage before incubation (Silva et al., 2008).

\section{CONCLUSIONS}

Pre-storage heating for six hours of eggs stored for four or nine days increases small intestine weight of newly-hatched chicks, but does not influence the morphology of the duodenal mucosa.

Pre-storage heating for 12 hours negatively influences body weight and duodenal mucosa development of newly-hatched chicks, and therefore this practice is not recommended.

Storage length does not have consistent effect on body weight and development of the gastrointestinal tract of newly-hatched chicks.

\section{REFERENCES}

Bigot K, Mignon-Grasteau S, Picard M, Tesseraud S. Effects of delayed feed intake on body, intestine, and muscle development in neonate broilers. Poultry Science 2003; 82:781-788.

Christensen VL, Wineland MJ, Fasenko GM, Donaldson WE. Egg storage alters weight of supply and demand organs of broiler chicken embryos. Poultry Science 2002; 81:1738-1743.

Corless AB, Sell JL. The effects of delayed access to feed and water on the physical and functional development of the digestive system of young turkeys. Poultry Science 1999; 78:1158-1169.

Denbow DM. Gastrointestinal anatomy and physiology. In: Whittow GC, editor. Sturkie's avian physiology. $5^{\text {th }}$ ed. San Diego: Academic Press; 2000. p. 299-325.

Fasenko GM, Robinson FE, Whelan Al, Kremeniuk KM, Walter JA. Prestorage incubation of long-term stored broiler breeder eggs: 1. Effects on hatchability. Poultry Science 2001; 80:1406-1411.

Geyra A, Uni Z, Sklan D. Enterocyte dynamics and mucosal development in the posthatch chick. Poultry Science 2001; 80:776782.

Haque MA, Pearson JT, Hou P-CL, Tazawa H. Effects of preincubation egg storage on embryonic functions and growth. Respiration Physiology 1996; 103:89-98.

Lilja C, Olsson U. Changes in embryonic development associated with long-term selection for high growth rate in Japanese quail. Growth 1987; 51:301-308.

Maiorka A, Santin E, Dahlke F, Boleli IC, Furlan RL, Macari M. Posthatching water and feed deprivation affect the gastrointestinal and intestinal mucosa development of broiler chicks. Journal of Applied Poultry Research 2003; 12:483-492.

SAS Institute. SAS user's guide: Sstatistics, version 8. Cary; 1999.

Silva FHA, De Faria DE, Torres KAA, De Faria Filho DE, Coelho AAD, Savino VJM. Influência dos tempos de aquecimento préarmazenamento e de armazenamento de ovos sobre o rendimento de incubação. Revista Brasileira de Ciência Avícola 2008; 10(1):1722.

Tona K, Bamelis F, De Ketelaere B, Bruggeman V, Moraes VMB, Buyse J, Onagbesan O, Decuypere E. Effects of egg storage time on spread of hatch, chick quality, and chick juvenile growth. Poultry Science 2003; 82:736-741.

Uni Z, Tako E, Gal-Garber O, Sklan D. Morphological, Molecular, and functional changes in the chicken small intestine of the lateterm embryo. Poultry Science 2003a; 82:1747-1754.

Uni Z, Smirnov A, Sklan D. Pre- and posthatch development of goblet cells in the broiler small intestine: effect of delayed access to feed. Poultry Science 2003b; 82:320-327.

Uni Z, Noy Y, Sklan D. Posthatch development of small intestinal function in the poult. Poultry Science 1999; 78:215-222. 